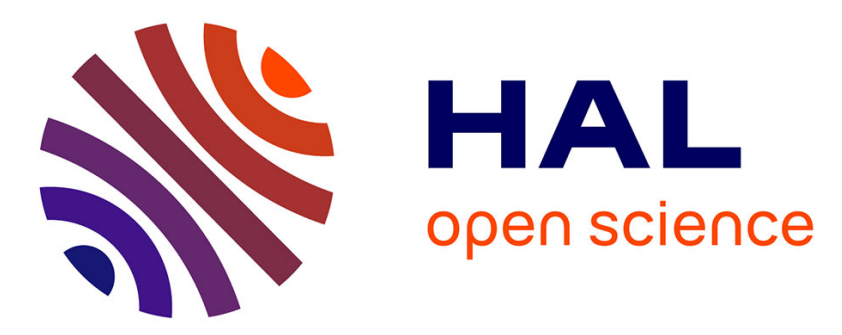

\title{
Study of the behavior of AC discharges of water drops on both conducting and dielectric solid surfaces
}

\author{
Adolphe Moukengué Imano, Abderrahmane Beroual
}

\section{To cite this version:}

Adolphe Moukengué Imano, Abderrahmane Beroual. Study of the behavior of AC discharges of water drops on both conducting and dielectric solid surfaces. IEEE Transactions on Dielectrics and Electrical Insulation, 2010, 17 (5), pp.1569 - 1575. 10.1109/TDEI.2010.5595559 . hal-00539059

\section{HAL Id: hal-00539059 \\ https://hal.science/hal-00539059}

Submitted on 25 Mar 2011

HAL is a multi-disciplinary open access archive for the deposit and dissemination of scientific research documents, whether they are published or not. The documents may come from teaching and research institutions in France or abroad, or from public or private research centers.
L'archive ouverte pluridisciplinaire HAL, est destinée au dépôt et à la diffusion de documents scientifiques de niveau recherche, publiés ou non, émanant des établissements d'enseignement et de recherche français ou étrangers, des laboratoires publics ou privés. 


\title{
Study of the Behavior of AC Discharges of Water Drops on both Conducting and Dielectric Solid Surfaces
}

\author{
Adolphe Moukengué Imano \\ University Institute of Technology \\ University of Douala \\ B.P. 8698 Douala, Republic of Cameroon \\ and Abderrahmane Beroual \\ Laboratoire Ampère, CNRS UMR 5005 \\ Ecole Centrale de Lyon \\ 36 Av. Guy de Collongue, 69134 Ecully cedex, France
}

\begin{abstract}
This paper presents the results of a study carried out on the deformation of a water surface and the effect water drops have on both conducting and dielectric solid surfaces subjected to a 50-Hz-volage stress. Also, contained in it are fundamental observations of current discharges characterizing water drops and metal electrode configurations as well as those configurations resulting from a flat water surface and a metal electrode. The measurements taken with both rod and point electrodes also came under investigation. The inception field strength of partial discharges between water surface and metal electrodes is analyzed. The discharge activities between water drops and between a conducting water drop and a small rod electrode on a flat hydrophobic insulator are also investigated. The results obtained characteristics of show typical discharge current during the discharge inception and development with and without water filaments, with regard to drop-drop and drop-rod configurations on the dielectric solid surface. This experimental study provides a better understanding of the processes leading up to flashover of hydrophobic insulators through discharges between water drops resulting of the distortion of these drops.
\end{abstract}

Index Terms - Sessile drop, drop distortion, outdoor insulation, field strength, partial discharges, current discharges.

\section{INTRODUCTION}

THE dynamics of the water drops on certain surfaces of high voltage equipments under ac voltage stress can produce complex dynamic shapes such as sideways wobbling and other modes of volumetric vibrations. Therefore, each deformed sessile drop on this dielectric or conducting solid surface disturbs clearly the electric field in their surroundings. This disturbance of the background field is attributed to the field enhancement on the deformed surface of the water film or each water drop, which is a positive feedback phenomenon governing the discharge activities around this water drop or water film.

Water drops or water films in high voltage equipment, why and where did that occur? The answer to this question allows us to classify the high voltage equipment in indoor and outdoor equipment.

In indoor high voltage equipment, for example high voltage switchgear and bus bars, synthetic materials are frequently used and the surfaces of this class of material can

Manuscript received on 29 October 2009, in final form 22 March 2010. accumulate water drops. These accumulated water drops can also later become water films. A very severe condition depositing drops on material surface is encountered when condensation occurs and a classical situation where this occurs is after a cold night, when the sun starts to heat the outer surfaces of a switchgear cubicle. The air heats up rapidly, but the solid insulation and massif conductors remain cold and condensation appears on these surfaces. In practice condensation starts with thousands or millions of micrometer size drops which spring up at microscopic defect sites on the surfaces. Growth and subsequent coalescence of adjacent drops leads to a water film or to larger drops surrounded by many smaller ones on a background of micron sized drops [1-3].

For outdoor high voltage equipments, rainwater drops are usually deposited on the surfaces of exposed equipment parts during or after precipitation. So by, conductors of overhead lines and sheds of outdoor insulators are those of most equipment parts, which can considerably accumulate multiple water drops on the surfaces [4-8]. Several water drops can also merge and naturally become water films on the wet solid surfaces. 
So far, and in our opinion, very few papers deal with experimental studies of the ac discharge behavior of water pollution on both conducting and insulated solid surfaces. Roero et al [4] investigate the behavior of drops on different high voltage conductors showing high framing rate records of their periodic deformation in the electric field. Danikas et al present in [9] an experimental study on the problems arising from the application of uniform ac electric fields on water droplets, which are on polymer surfaces. Keim [10] investigates experimentally, the behavior of droplets on polymeric surfaces under the influence of an applied electrical field. She shows experimentally that the forming of water paths between the droplets follows the direction of the applied electric field. Karakoulidis et al show in [11] that water droplet conductivity, polymer surface roughness, droplet volume and droplet positioning affect the droplet behavior. Swift [12] and Mizuno et al [13] investigate ac flashover and mechanism for water drops on non-ceramic insulator. We also investigated the deformation of two water drops placed on the dielectric solid surface between both metal electrodes under $50 \mathrm{~Hz}$ ac voltage stress elsewhere [14], and we observed that only the nearest drop to the one of the electrodes elongates asymmetrically. In this way, it was elucidated that this is due to the fact that the forces acting on the drop point nearest to one of the electrodes is the highest resulting of the effect of the image force. The field strength (thus the electric force) at this drop point depends on the radius of the curvature of the drop tips, and also precisely on the deformation of a drop surface. Furthermore, it was observed that the influence of these water drops on the flashover mechanism along the insulated surface is largely determined by the shape of each drop. It is well known, that under ac field stress a water drop can be deformed in the direction of the electric field, and in turn, will disturb the electric field through formation of high local field strengths in its immediate surroundings. This local field strength can lead to increasing drop elongation accompanied by the reduction of the shorter distance between both the lower and the high voltage electrodes, or between both tips of the outdoor insulator. Evidently, the electric stress provoked on the material may differ in accordance to the geometry of the electric field near the surface. Therefore it is of great interest to carry out an investigation on the impact of partial discharges between water drops while reproducing the conditions encountered at different areas of the insulator. Moreover, for a better understanding of the phenomenon leading to elongation of sessile water drops, the investigation of the behavior of electric force acting at a water surface is also necessary.

The aim of this paper is to present the results of performed investigations of ac discharge behavior of water drops on both conducting and dielectric solid surfaces. Why investigate firstly the instability of an electrified water drop and water surface? Precisely, we regard the initiation of the discharges and the development of the discharges between water/air interface and a metal electrode. The results of this investigation can also provide a better understanding of the approach used elsewhere [15] to calculate the field inhomogeneity factor according to Schwaiger [16]. In this approach used to simulate the deformation of a sessile drop on dielectric solid surface, the radius of curvature at the drop pole was assimilated to a virtual sphere according to Taylor [17].

Furthermore, this paper also investigates the discharge activities between two conducting water drops on a dielectric solid surface, when a constant ac voltage is applied on both drops through an experimental electrode arrangement. The partial discharge development between a single water drop and an electrode on the dielectric solid surface was also observed and presented.

\section{EXPERIMENTAL DETAILS}

\subsection{EXPERIMENTAL SETUP}

Figure 1 shows the test electrode arrangement with an electrodes arrangement (Test). The rod or point electrode is connected through a high voltage resistance $\left(R_{p}\right)$ of $100 \mathrm{M} \Omega$ to the ac high voltage source and the plate electrode connected to ground. The electrodes arrangement "Test" is replaced by one or more than one water drops placed on the surface of a flat hydrophobic insulator.

The applied ac voltage on the electrodes arrangement is measured using a Tektronix P6015A high voltage probe (TEK 2). The potential drop across the resistance $\mathrm{R}_{\mathrm{I}}(75 \Omega, 1 / 4 \mathrm{~W})$ is fed directly to the digital storage oscilloscope (Tektronix, TEK 1) to measure the discharge current characteristics. ac voltage was supplied from a single phase $230 \mathrm{~V} / 50 \mathrm{kV}$ test transformer.

The behavior of drops on the insulator surface and the behavior of the drop surface or water surface were recorded by using a CCD-IRIS video camera. For water drops and generally water surface, we also used normal drinking water with a conductivity of $320 \mu \mathrm{S} / \mathrm{cm}$.

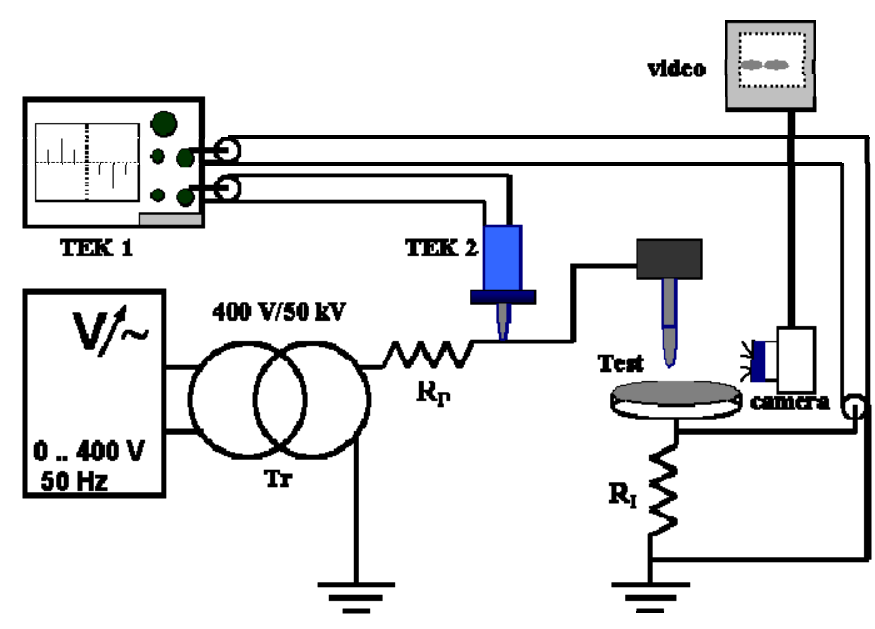

Figure 1. Experimental setup 
The investigation of discharge behavior of water drop on conducting surface was performed for sessile water drop with a volume of $50 \mu \mathrm{l}$, as shown in Figure 2 for the point-

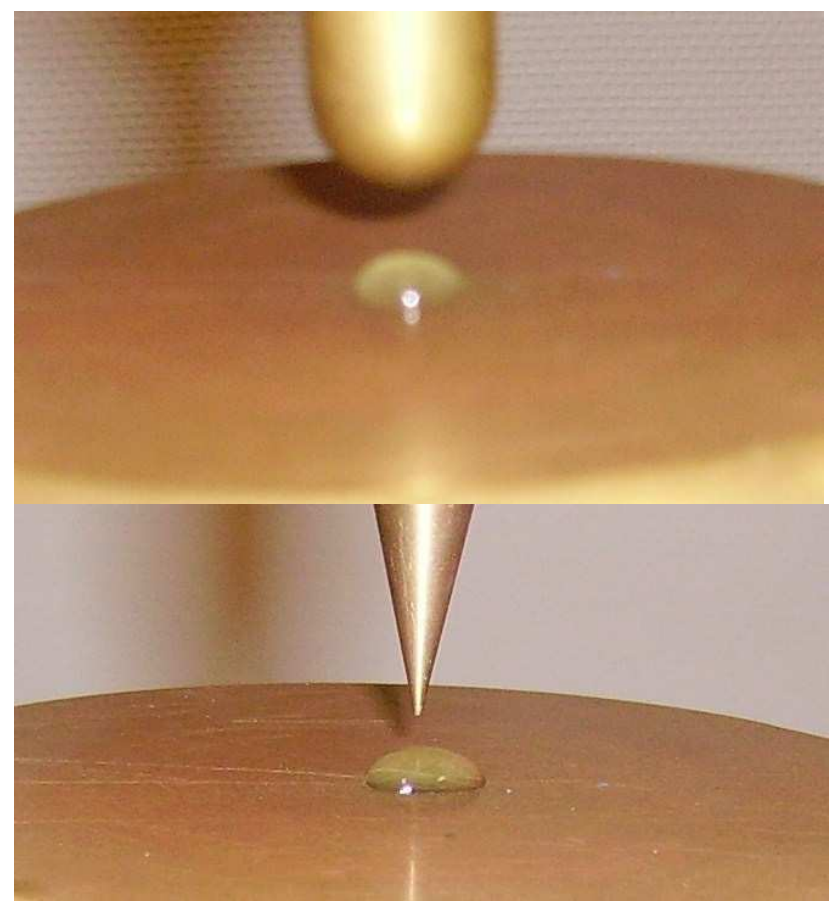

Figure 2. Point-Plate and Rod-Plate electrode arrangements.

plate electrodes arrangement and for rod-plate ones. Furthermore, for the flat water surface configuration we used a specially shaped electrode which is made of stainless steel and which can contain up to $10 \mathrm{ml}$ water, as shown in Figure 3 with point electrode.

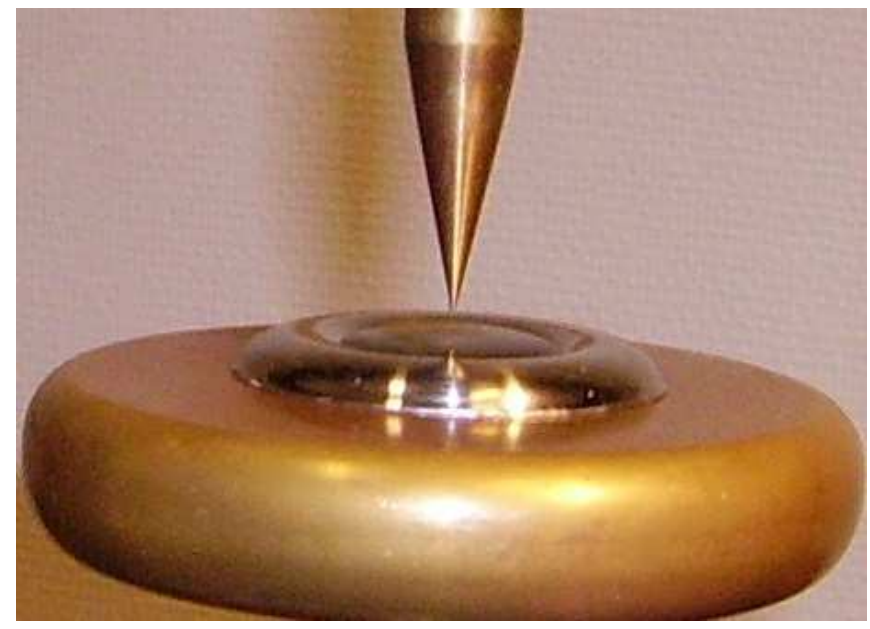

Figure 3. Water surface with the point electrode.

As regards investigations on discharge behaviour of one or more water drops on dielectric solid surface, we used only sessile water drops, and the volume of each drop was $10 \mu 1$. One or both water drops are connected respectively to two electrodes, and both electrodes are separated by a gap distance of $10 \mathrm{~mm}$. One electrode is connected through a high voltage resistance $R_{p}$ to the AC high voltage source and the other electrode connected to ground.

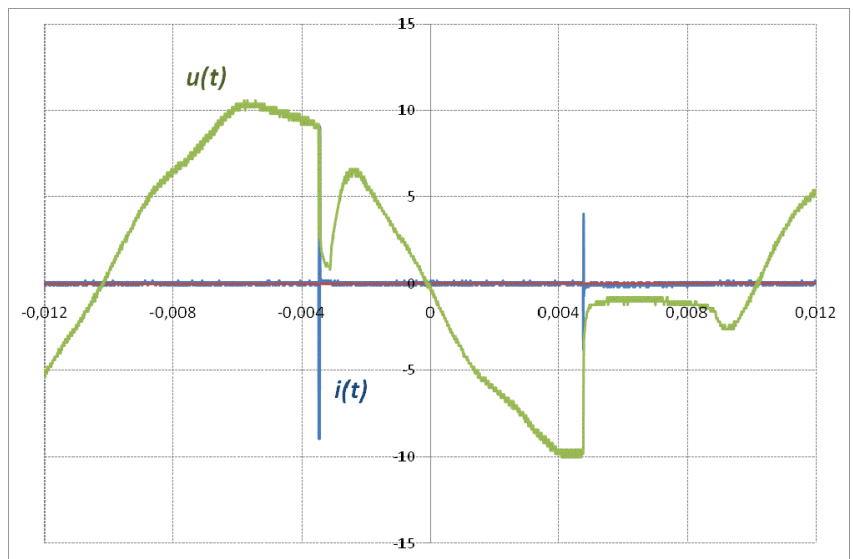

Figure 4. Typical voltage and current measured during a discharge development for a sessile drop placed at a distance of $6.13 \mathrm{~mm}$ to the rod electrode.

\subsection{DETERMINATION OF THE PD INCEPTION FIELD STRENGTH}

The $50 \mathrm{~Hz}$ voltage was increased gradually until the first partial discharges (PD) occurred. The exact value of the PD inception voltage and the voltage shape were recorded with a digital storage oscilloscope (Tektronix).

The measurements for the determination of the $\mathrm{PD}$ inception field strength have been evaluated according to the proposed method of IEC 60060/2. It is assumed that all experiments are normally distributed. The indicated bars in Figures 8 and 9 of sections 3.3 and 3.4 show the $95 \%$ confidence interval of the expected values.

\section{WATER DROP AND WATER FILM ON METAL ELECTRODE \\ 3.1 THE INSTABILITY OF A SESSILE WATER DROP}

The investigated sessile water drop is illustrated in Figure 2. A potential $\hat{U}$ of up to $= \pm 15 \mathrm{kV}$ could be applied to the water drop by means of continuous variable power supply. Higher values of potential tended to cause the drop surface to become instable for a drop faced to the point electrode, and the drop to move up from plane electrode to rod electrode. The camera presented in Figure 1 made it possible for the drop to be observed and photographed before and after the course of each experiment. The experiments were performed for five different distances from the top of the drop to the faced electrode: $3.18 \mathrm{~mm}$, $4.14 \mathrm{~mm}, 5.24 \mathrm{~mm}, 6.13 \mathrm{~mm}$ and $7.23 \mathrm{~mm}$.

Figure 4 shows typical discharge development for a sessile drop placed at a distance of $6.13 \mathrm{~mm}$ to the rod electrode, and for a full period of $50-\mathrm{Hz}$ voltage. The behavior of the recorded voltage shows that when the applied voltage reached a certain value, a current began to flow between the metal electrode and the drop. This current can become stable (established current) or instable (current 
impulses). The current impulses are bidirectional and do not act identically in positive and negative half waves of the voltage. In the same way, it was observed that the current discharges of a sessile drop faced to the point electrode show a similar behavior.

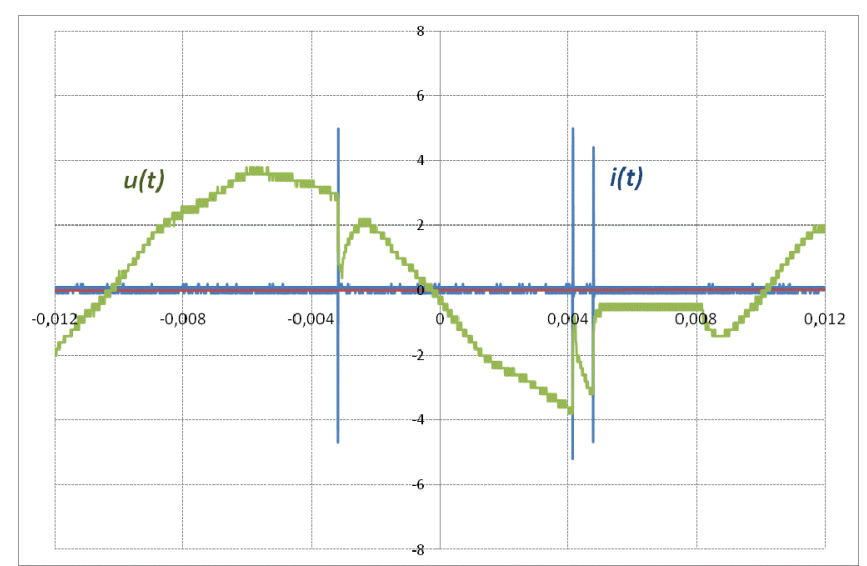

Figure 5. Typical voltage and current measured during a discharge development for a water/air interface at spacing of $1.18 \mathrm{~mm}$ to the point electrode.

\subsection{THE INSTABILITY OF AN ELECTRIFIED WATER/AIR INTERFACE}

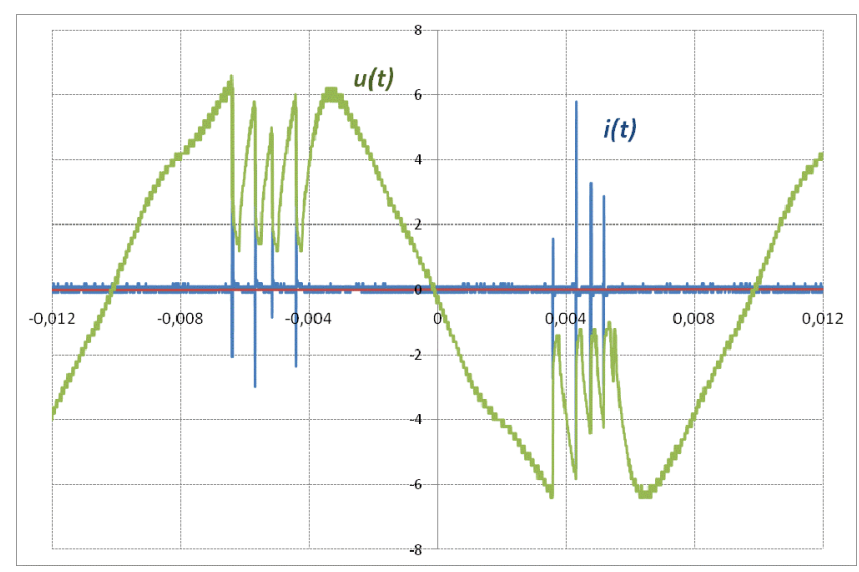

Figure 6. Typical voltage and current measured during a discharge development for a water/air interface at spacing of $3.18 \mathrm{~mm}$ to the rod electrode.

Figures 5 and 6 illustrate the typical behavior of voltage and current discharges observed when the water surface is subjected to $50 \mathrm{~Hz}$ electric field for both point and rod electrodes. The instability of water/air interface is thereby evidenced through the flow of current impulses in the gap due to corona discharges on the water surface. This instability is also characterized by the vibration or motion of the water/air interface. This can be observed through the behavior of current discharges. The current impulses are bidirectional and act identically in both positive and negative half waves of the voltage. We can also note that, partial discharges do not take into account the polarity of the voltage.

Figure 7 gives an illustration that clearly shows how the initially flat water surface is locally deformed until it bridges the gap or until a breakdown occurs at the protrusion tip. The same phenomenon can also be of considerable importance in Gas circuit breakers through

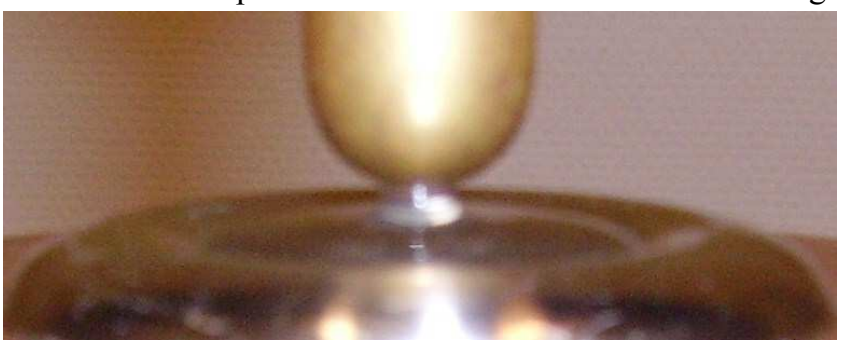

Figure 7. Motion of the water/air interface with the rod electrode.

molten metal triggered breakdown, if the breakdown field is high, as with $\mathrm{SF}_{6}$ at pressures of 0.3 to $0.6 \mathrm{MPa}$ (3 to 6 bars) [18].

\subsection{THE PD INITIATION FIELD STRENGTH FOR A SESSILE DROP FACED TO METAL ELECTRODES}

The initiation voltage of the partial discharges (PD) between a drop surface and that of a metal electrode depends on the geometry of the used electrode, and also on the distance between the top of drop and the electrode. Figure 8 shows the behavior of the PD inception field strength of the drop surface facing respectively to rod and point electrodes, with respect to spacing. This field strength gives the critical condition for the stability of the drop shape, and is observed for spacing up to $7.23 \mathrm{~mm}$. It can also be observed, that for relative small gap distances the drop surface will become quickly unstable for the rod electrode. However, the drop surface becomes most unstable when the gap distance increases, for the point electrode.

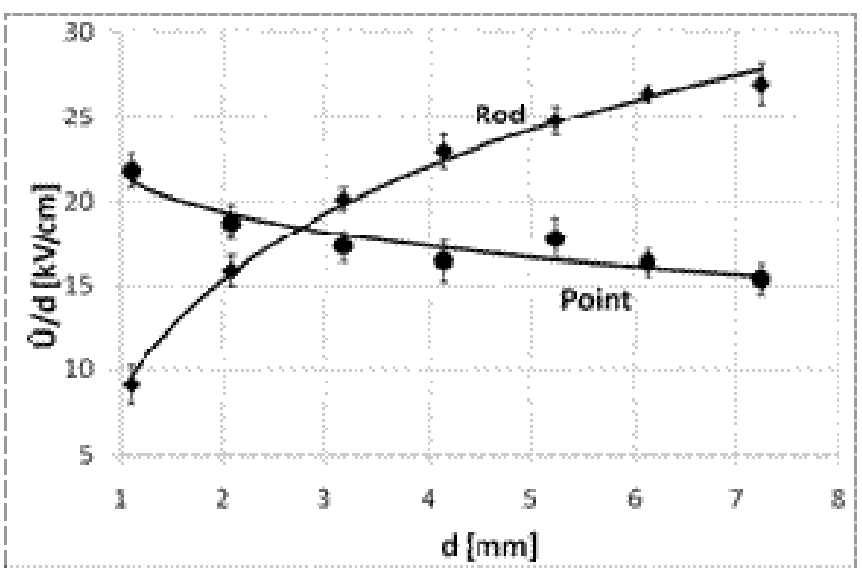

Figure 8. PD inception field strength for a sessile drop versus spacing (d) with different forms of the metal electrode. 


\subsection{THE PD INITIATION FIELD STRENGTH FOR A WATER/AIR ITERFACE FACED TO DIFFERENT METAL ELECTRODES}

A water surface can become unstable when subjected to an electric field and when the field strength reaches the relative critical value. The mechanism which comes into play under these conditions is the electrostatic deformation of the water surface. This was observed for spacing up to $9.18 \mathrm{~mm}$. Below this spacing, PD initiation fields are

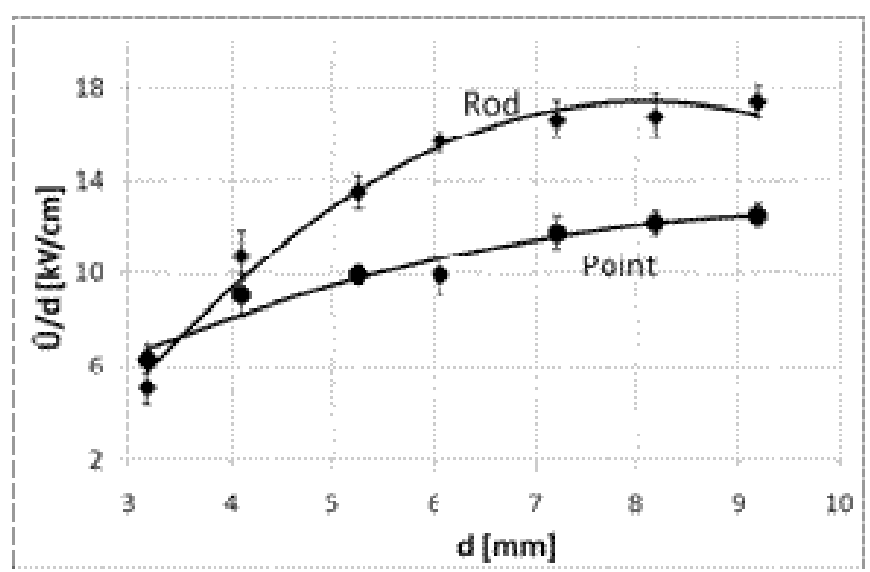

Figure 9. PD inception field strength for a water/air interface versus spacing (d) with different forms of the metal electrode.

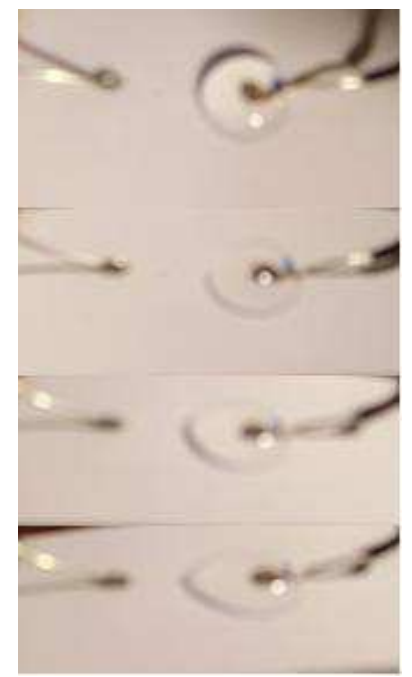

Figure 10. Deformation of an electrified single water drop faced to a small rod electrode.

generally found to be lower for both point and rod electrodes, as shown in Figure 9. Nevertheless, the water surface becomes unstable for lower field strengths both with point electrode as with rod electrode.

\section{WATER DROPS ON DIELECTRIC SOLID SURFACE}

It is well known in general that when the drop is placed in a high electric field zone, corona discharge occurs at the edge of the water drop $[19,20]$. The same behavior can be clearly observed for one or two sessile drops connected to electrodes, and when both electrodes are stressed with ac voltage.

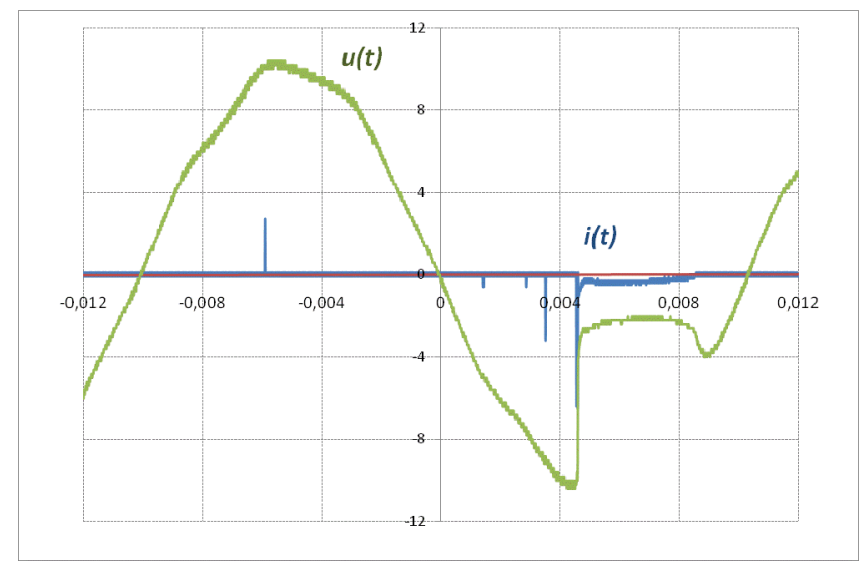

Figure 11. Typical voltage and current measured during a discharge development for a sessile drop connected to the high voltage, without water filaments.

\subsection{AC DISCHARGE CURRENT CHARACTERISTICS OF SINGLE WATER DROP}

Figure 10 shows four video pictures of the deformation of an electrified single water drop on the dielectric surface between. The drop was placed facing a small rod electrode. Furthermore, for a better understanding of the polarity effect on the current discharges with water drops, we connected the drop successively to a grounded conductor and to high voltage potential.

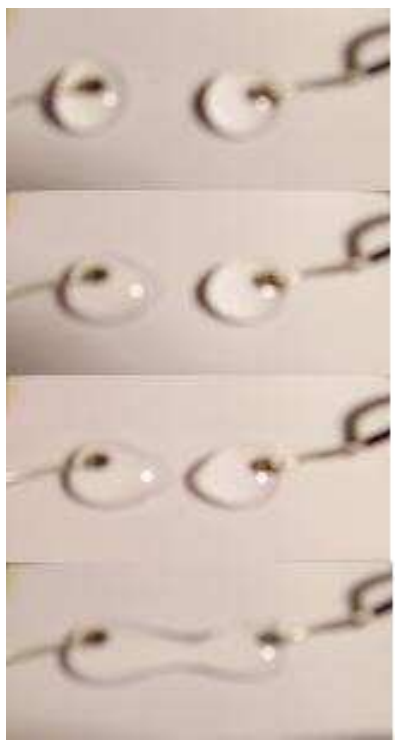

Figure 12. Deformation of a pair of electrified water drops.

These video pictures were recorded gradually when increasing the voltage up to the observed drop deformation. It is shown that the drop elongates asymmetrically in the direction the facing rod electrode with or without ejection of water filaments. We also observed that the shorter the distance between the drop and the electrode, the lower the potential leads to drop instability.

The mechanical instability of the stressed drop increases rapidly with the voltage stress until it forms a thin film at the drop tip. Figure 11 shows the instability state of the drop before 
formation of thin film along the insulator surface through typical current discharge characteristics. The current impulses are unidirectional and therefore do not act identically in positive and negative half waves of the voltage. Polarity effect is also observed through intensive PD activities from $-10 \mathrm{~ms}$ up to $0 \mathrm{~ms}$ for grounded drops, and from 0 up to $10 \mathrm{~ms}$ for drops connected to high voltage potential (as shown in Figure 11). However, this behavior of current discharges becomes different after formation of thin film along the insulator surface. The PD activities during the full period of $20 \mathrm{~ms}$ are most intensive, and are also characterized by closed current impulses caused by the elongation of the drop and forming of water filaments along the dielectric surface up to the small rod electrode.

\subsection{AC DISCHARGE CURRENT CHARACTERISTICS OF TWO WATER DROPS}

Figure 12 shows four video pictures of the deformation of a pair of water drops. One of both drops is connected to high voltage potential through a small conductor, another drop is grounded. When a sufficient ac voltage is applied on both two drops, they elongate one towards the other. Once spacing between the edges of both deformed drops becomes critical, the drops become mechanically unstable and eject water filaments one after the other.

Figure 13 illustrates the voltage and discharge current measured at the instant of discharge development with

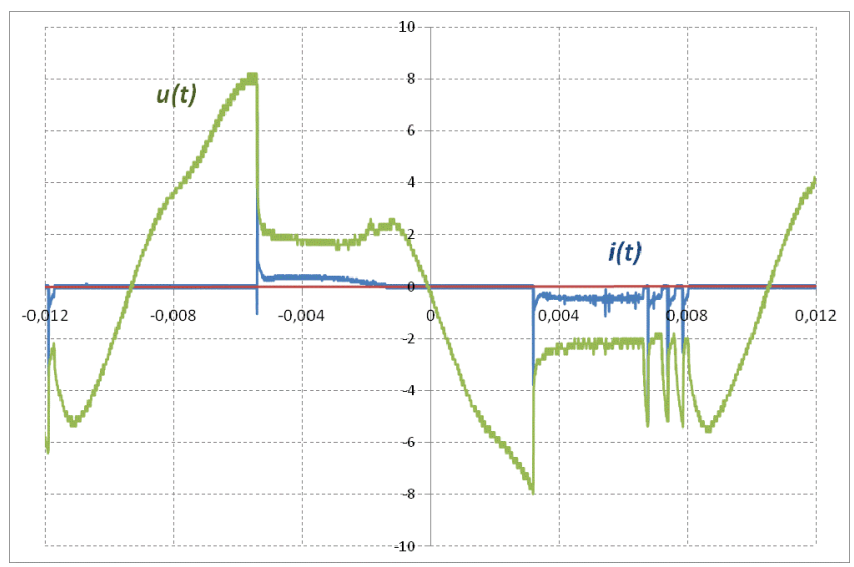

Figure 13. Typical voltage and current measured during a discharge development for a pair of sessile drops, with filaments.

formation of water filaments. It was also observed that the drops can elongate or vibrate without discharge activities under certain conditions. The mechanical instability of each drop increases rapidly with the voltage stress until flashover or until formation of thin film between both drops. This is also illustrated in the Figure 12.

\subsection{AC DISCHARGE CURRENT CHARACTERISTICS OF THREE ALIGNED WATER DROPS}

Figure 14 show three video pictures of the deformation of two electrified drops with an inserted third drop. One of both extreme drops is connected to high voltage potential through a small conductor and another drop is grounded. The inserted drop is aligned to other drops. In Figure 14, the voltage was increased until the deformation of the drops

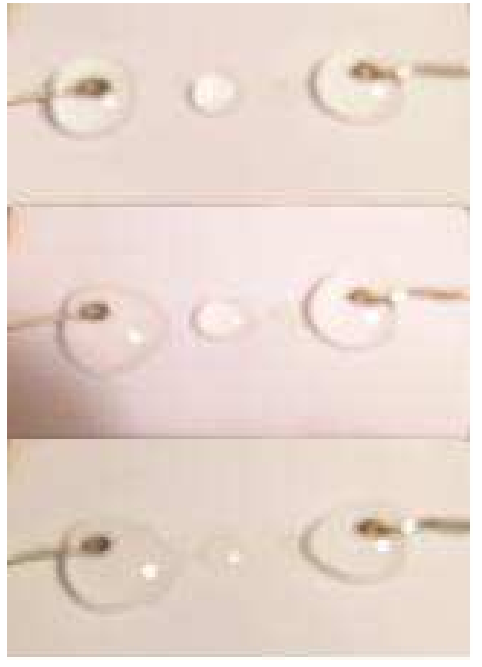

Figure 14. Deformation of a pair of electrified water drops with inserted third drop.

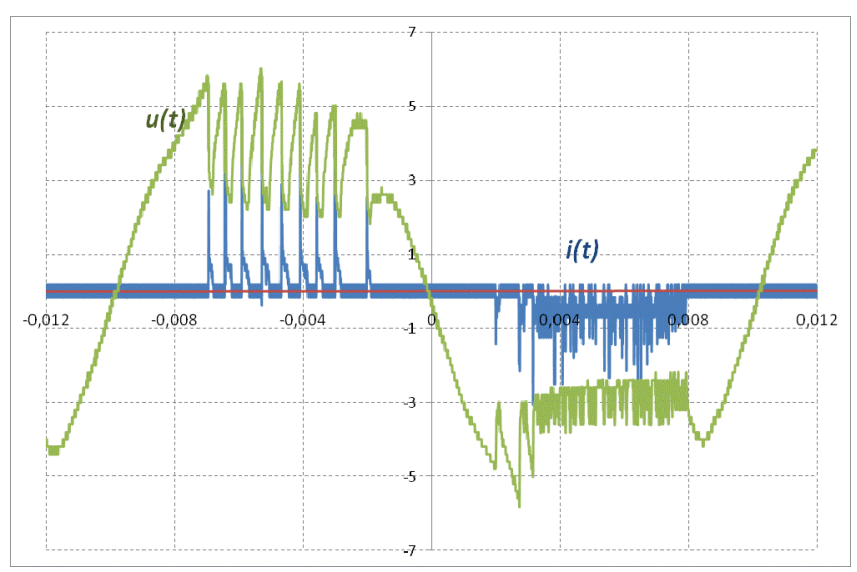

Figure 15. Typical voltage and current measured during a discharge development for a pair of sessile drops with inserted third drop, with water filaments.

occurred. It is observed that the three drops will elongate and their spacing one to another will decrease too. The phenomenon can be attributed to the mutual interaction forces between the drop tips. Finally, the drop in the centre disintegrates and moves partially to both extreme drops and coagulates there. These drops become consequently voluminous.

In Figure 15, a typical characteristic of current discharges of three aligned water drops is shown. Also through also the behavior of the applied voltage during the recoded full period of $20 \mathrm{~ms}$, the vibration or the instability of the three drops can be observed. Precisely, the instability of the drops is characterized by impulse current, when a sufficient voltage is applied.

\section{CONCLUSION}

In this paper we investigated the behavior of corona discharges between a metal electrode and water surface under $50 \mathrm{~Hz}$ ac voltage stress. The instability of water/air interface is hereby evidenced through the flow of current impulses in the gap due to corona discharges on the water surface. 
Other obtained results enable us also to affirm, that the electric field applied to the water surface is controlled by the electrode geometry and spacing between water surface and the electrode. Furthermore, the determinate PD initiation field strengths for rod electrode provide relevant inputs for the field inhomogeneity used in the simulation of the deformation of aligned water drops.

In the same way, we also investigated the current discharge characteristics of water drops on dielectric solid surface made from silicone rubber (SIR), under $50 \mathrm{~Hz}$ ac voltage stress. Current discharges appeared and were measured. It was found that the length of a discharge between drops or between a single drop and a small rod electrode is reduced through a particular type of its distortion. This is visually characterized by a water filament or thin film between the water drops along the insulator surface.

\section{ACKNOWLEDGMENT}

The authors would like to thank the Ecole Centrale de Lyon, France, for financial support.

\section{REFERENCES}

[1] J. W. Rose and L. R. Glicksman, "Dropwise Condensation - The distribution of Drop Sizes", J. heat Mass Transfer, Vol. 16, pp. 411425, 1973.

[2] S. J. Gokhale, J. L. Plawsky, and P. C. Wayner , "Experimental investigation of contact angle, curvature and contact line motion in dropwise condensation and evaporation", J. of Coloid and Interface Sci., Vol. 259, pp. $354-366,2003$.

[3] T. Kimura and S. Maruyama, "Molecular dynamics simulation of heterogeneous nucleation of a liquid droplet on a solid surface", Microscale thermophysical Engineering, Vol. 6, pp. 3 - 13, 2002.

[4] C. Roero and T. H. Teich, "Water drops on high voltage transmission lines", Electrostatics Society of America (ESA) Annual Meeting University of Alberta, Edmonton, Canada, 2005.

[5] U. Straumann and M. Semmler, "About the mechanism of tonal emission from high voltage lines", 15th Int. Conf. on Gas Discharges and Their Applications, Toulouse, France, Vol. 1, pp. 363-366, 2004.

[6] G. G. Karady. "Flashover Mechanism of Non-ceramic Insulators", IEEE Trans. Dielectr. Insul., Vol. 6, pp. 718-723, 1999.

[7] R. S. Gorur, E. A. Cherney and J. T. Burnham, Outdoor Insulators, Ravi S. Gorur Inc., 1999.

[8] M. Amin, M. Akbar and S. Amin, "Hydrophobicity of Silicone Rubber used for Outdoor Insulation (an overview)", Rev. Adv. Mater. Sci. Vol. 16, pp. 10-26, 2007.

[9] M. G. Danikas, P. Rakitzis and K. Karakoulidis , "Study of parameters related to deterioration phenomena due to water droplets on polymeric surfaces", J. Electr. Eng., Vol. 57, No. 3, pp. 130-137, 2006.

[10] S. Keim, Optical Diagnostic of Single Droplets on Polymeric Insulating Surfaces in an Electric Field: A Contribution to the Characterization of Phenomena Initiating Aging Mechanisms, Ph.D Thesis, Darmstadt University of Technology, Germany, 2003.

[11] K. Karakoulidis M. G. Danikas and P. Rakitzis, "Deterioration phenomena on polymeric insulating surfaces due to water droplets", J. Electr. Eng., Vol. 56, no. 7-8, pp. 169-175, 2005.

[12] D. A. Swift, "AC Flashover mechanism for water droplets on a hydrophobic insulator ", $8^{\text {th }}$ Intern. Symposium on High Voltage Engineering, Yokohama, Japan, 1993.

[13] Y. Mizuno, M. Iwatani, M. Nagata, K. Naito, K. Kondo and S. Ito, "Behaviour of water Droplet on Silicone Rubber Sheet under AC Voltage Application ", IEEE Conf. Electr. Insul. Dielectr. Phenomena (CEIDP), Vol. 1, pp. 96-99, 1999.

[14] A. M. Imano and A. Beroual, "Deformation of water droplets on solid surface in electric field", J. Colloid and Interface Sci., Vol. 298, pp. 869-879, 2006.
[15] A. M. Imano, S. Ndjakomo Essiane, A. Beroual, "Simulation of the shapes of a water droplet on insulated solid surface in an AC electric field", Canadian J. Phys., Issue 85, pp. 1-17, 2007.

[16] A. Schwaiger, Elektrische Festigkeitslehre, Springer-Verlag Berlinigré, 1925.

[17] G. I. Taylor, "Disintegration of water drops in an electric field", Proc. Roy. Soc., A, Vol. 280, 383-397, 1964.

[18] S. Rowe, "Consideration of breakdown of some specific electrical engineering situations", $7^{\text {th }}$ intern. Conf. Gas Discharges and their Applications, Cardiff, UK, pp. 17-32, 2008.

[19] S. M. Rowland and F. C. Lin. "Stability of alterning current discharges between water drops on insulation surfaces", Phys. D: Appl. Phys., Vol. 39, pp. 3067-3076, 2006.

[20] R. Srathi, G. Nagesh and K. Vasudevan, "Classification of discharges initiated by liquid droplet on insulation material under $\mathrm{AC}$ voltage adopting UHF technique", Proc. World Academy of Sci., Eng. Techn., Vol. 29, pp. 177-182, 2008. .

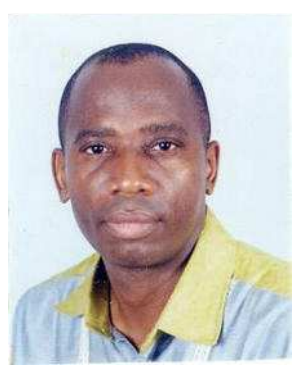

A. Moukengué Imano was born in Ebolowa, Cameroon in 1964. He studied electrical engineering at the Technical University of Dresden, Germany, and graduated (Dipl.-Ing) in 1992. Subsequently, he was employed as Engineer at Lech-Elektrizitätswerke AG Augsburg, Germany. From 1993 to 1998, he worked in Cameroon, respectively at AES-SONEL, Ingénieurie Services JP Stynen Yaoundé and at the University Institute of Technology of the University of Douala, as Lecturer. In April 1998, he joined the Institute of Power Transmission and High Voltage Technology of the University of Stuttgart, Germany, from which he received the Ph.D. degree in 2001. Currently Dr. Adolphe Moukengué Imano is Senior Lecturer and Head of the Electrical Power and HV Research Group at the University Institute of Technology of the University of Douala, Cameroon. His research activity includes high pressure dielectric gases/gas mixtures, discharges at dirty surfaces (insulators and deflectors) and simulation of transients in networks.

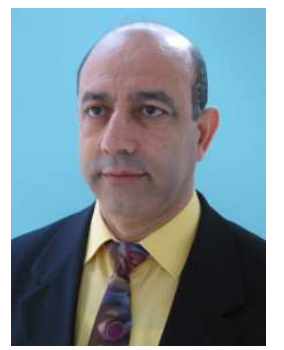

Abderrahmane Beroual (M'92-SM'09) received the Dipl. Ing. and Ph.D. degrees in electrical engineering, respectively in 1976 from the Ecole Nationale Polytechnique of Algiers, Algeria and in 1979 from the Technical University of Wroclaw, Poland. In 1987, he obtained the Doctorat d'Etat ès Sciences Physiques degree from the Institut National Polytechnique of Grenoble, France. In 1980, he joined the Department of Electrical Engineering at the Ecole Nationale Polytechnique of Algiers. From 1983 to 1987, he was a researcher at the Laboratoire d'Electrostatique et de Matériaux Diélectriques (LEMD) - CNRS of Grenoble, France and associate professor at the Joseph Fourier University of Grenoble. He received the title of professor at the Ecole Nationale Polytechnique of Algiers in 1987. In 1989, he joined the Ecole Centrale de Lyon, France where he is presently professor and the head of the Dielectric Materials and High Voltage Group at AMPERE Lab - CNRS as well as the Responsible of the Master Research Program in Electrical Engineering. He is responsible of numerous research projects. His main research interests include high voltage insulating, dielectric materials, long air discharge and lightning, modeling of discharges and composites. He is author/co-author of more than 300 technical papers including four patents, more than 110 refereed journal papers and four book chapters. He supervised more than $34 \mathrm{PhD}$ and doctorat d'Etat ès Sciences. He was the leadership of the International Study Group on Streamer Propagation in Liquids of the IEEE - DEIS (1994 - 1998). He is on many Advisory Committees of International Conferences (ICDL, ISH, APTADM, Gas Discharge, ICHVE, CMD, INSUCON, NIWE, iREED). 